$$
\begin{array}{ll}
\text { Volume } & : 05 \\
\text { Nomor } & : 02 \\
\text { Bulan } & : \text { Mei } \\
\text { Tahun } & : 2019 \\
\text { http } & : / / \text { ejurnal.pps.ung.ac.id/index.php/AKSARA/index }
\end{array}
$$

\title{
KONTRIBUSI BELAJAR JARAK JAUH MAHASISWA TINGGAL DI DESA TERPENCIL
}

\author{
Samiun Husain \\ Universitas Terbuka \\ Samiun_husain@yahoo.co.id
}

Received: 29 Februari 2019; Revised: 12 April 2019; Accepted: 15 April 2019

\begin{abstract}
ABSTRAK
Hadirnya Universitas Terbuka dengan sistim belajar jarak jauh dapat menjawab masalah pemerataan pendidikan nasional, dapat menjangkau dan dijangkau oleh masyarakat yang tinggal di desa terpencil. Guru yang tinggal di desa terpencil yang sebelumnya tidak dapat melanjutkan pendidikan karena alasan jarak, waktu dan biaya, kini sudah dapat melanjutkan pendidikan program S1 PGSD di UPBJJ-Universitas Terbuka Gorontalo. Mahasiswa sudah dapat belajar mandiri melalui media cetak dan non cetak yaitu media yang sudah dirancang khusus untuk dapat dipelajari sendiri sebagai media utama yang digunakan dalam proses belajar jarak jauh di Universitas Terbuka.Mahasiswa yang mengajar didesa terpencil dapat melanjutkan pendidikan tanpa meninggalkan tugas pokok dan keluarga. Mendapat layanan bantuan belajar melalui tutorial tatap muka sehingga mereka belajar dapat berdiskusi dengan sesama teman dan antar kelompok yang dibimbing oleh seorang dosen atau tutor sebagai fasilitator, sehingga mahasiswa dalam belajar tidak merasa kesepian dan terisolir.

Kata Kunci UT dapat menjangkau, dijangkau masyarakat desa terpencil
\end{abstract}

\section{PENDAHULUAN}

Seiring dengan perkembangan ilmu pengetahuan dan teknologi disegala bidang, terutama dibidang pendidikan dan teknologi komunikasi yang begitu cepat, pendidikan jarak jauh dirasakan semakin dekat dan semakin menarik minat masyarakat. Kemajuan ini bukan saja dirasakan atau dinikmati oleh masyarakat yang perkotaan saja malah sampai pada masyarakat yang pedesaan atau masyarakat yang tinggal di desa terpencil.

Perkembangan dan kemajuan ini menuntut paradikma ( pola berfikir ) agar lebih luas dan maju ke depan, bahwa masyarakat tidak dapat mengikuti perkembangan tanpa ada pendidikan. Hanya pendidikan yang dapat menjembatani segala aspek kehidupan seperti: guru, pegawai, petani, tukang ternak, pedagang dan aspek-aspek kehidupan lainnya.

Universitass terbuka dengan sistim belajar jarak jauh yang dimediasi dengan bahan ajar cetak dan non cetak telah mampu menjawab permasalahan agar pendidikan dilaksanakan secara merata, artinya pendidikan untuk semua, bukan hanya menjadi milik masyarakat tertentu yang tinggal di perkotaan tetapi juga adalah menjadi milik masyarakat yang bertempat tinggal di pedesaan atau yang tinggal di desa terpencil.

Di Kabupaten Gorontalo Kecamatan Asparaga terdapat suatu desa terpencil yaitu desa Bululi, terdapat kelompok belajar mahasiswa program S1 PGSD yang sedang belajar di Universitas Terbuka dan sudah duduk disemester enam yang belum diketahui bagaimana 


$$
\begin{array}{ll}
\text { Volume } & : 05 \\
\text { Nomor } & : 02 \\
\text { Bulan } & : \text { Mei } \\
\text { Tahun } & : 2019 \\
\text { http } & : / / \text { ejurnal.pps.ung.ac.id/index.php/AKSARA/index }
\end{array}
$$

kontribusi atau manfaatnya bagi mereka belajar jarak jauh, untuk mengetahuinya perlu dilaksanakan penelitian.

Pada prinsipnya Universitas Terbuka memberikan kesempatan bagi setiap insan yang ingin menikmati pendidikan tinggi, karena berdirinya Universitas Terbuka bertujuan untuk:

1. Memberikan kesempatan seluas-luasnya bagi warga Negara Indonesia (WNI) dan warga Negara asing ( WNA ) dimana pun tempat tinggal mereka untuk memperoleh pendidikan tinggi.

2. Memberikan layanan pendidikan tinggi bagi mereka yang bekerja atau karena alasan lain tidak dapat melanjutkan belajar pada perguruan tinggi tatap muka

3. Mengembangkan program pendidikan akademik dan provesional yang disesuaikan dengan kebutuhan nyata pembangunan, yang banyak dikembangkan oleh perguruan tinggi yang lain (katalog UT 2009).

Guru sebagai unjung tombak dalam meningkatkan mutu pendidikan harus menyesuaikan kemampuannya sesuai dengan tuntutan perkembangan di masyarakat. Mentri pendidikan dan Kebudayaan sejak tahun 1989 dengan surat keputusanya No: 0854/8/1989 Tanggal 31 Desember 1989 tentang pengadaan dan penyetaraan guru sekolah dasar yang sedang berdinas ditingkatkan dari jenjang pendidikan lanjutan tingkat atas kejenjang Diploma (DII) (Brotosiswojo 1997) dan undang-undang guru dan dosen tahun 2005 lebih menekangkan bahwa guru harus berkualifikasi pendidikan sarjana atau D.IV.

Universitas Terbuka dengan sistem pendidikan jarak jauh proses pembelajarannya dimediasi oleh bahan ajar cetak dan noncetak pada dasarnya dapat menjangkau dan dapat dijangkau oleh kalangan masyarakat dimana dia tinggal. Demikian halnya guru yang terdaftar sebagai mahasiswa program S1 PGSD di UPBJJ-UT Gorontalo yang bertugas di daerah terpencil mereka menikmati pendidikan tinggi seperti di tempat-tempat yang lain.

Kelompok belajar mahasiswa yang bertugas di desa terpencil harus mendapat pelayanan pendidikan yang sama, bukan saja belajar mandiri atau mengatur belajarnya sendiri, tetapi juga dapat belajar melalui tutorial tatap muka yang dibimbing oleh seorang dosen atau tutor dan bertindak sebagai fasilitator dalam membantu mahasiswa yang mengalami kesulitan belajar agar mereka terbiasa belajar mandiri. Dengan proses pembelajaran ini mahasiswa tetap belajar di tempatnya sendiri tanpa meninggalkan tugas pokok mereka maasing-masing dan keluarga.

\section{TINJAUAN PUSTAKA}

\section{Belajar Jarak Jauh}

Universitas Terbuka adalah unuversitas terbesar di indonesia dengan menerapkan sistem belajar jarak jauh dan bersaing prestasi dengan pendidikan tinggi jarak jauh dengan negaranegara lain. Universitas Terbuka adalah perguruan tinggi yang ke 45 di indonesia yang di resmikan oleh presiden repoblik indonesia pada tanggal 4 september 1984 berdasarkan Kepres RI No 41 tahun 84 ( katalog UT 2009 ).

Sistim belajar jarak jauh berati belajar tidak melaksanakan tatap muka, melainkan dengan menggunakan media cetak berupa modul dan non cetak berupa kaset., VCD, dan melalui internet. Sedangkan terbuka mengandung makna tidak ada batasan usia, tahun ijazah, masa belajar, waktu registrasi, serta frekwensi mengikuti ujian.

104 AKSARA Jurnal Ilmu Pendidikan Nonformal 


$\begin{array}{ll}\text { Volume } & : 05 \\ \text { Nomor } & : 02 \\ \text { Bulan } & : \text { Mei } \\ \text { Tahun } & : 2019 \\ \text { http } & : \text { //ejurnal.pps.ung.ac.id/index.php/AKSARA/index }\end{array}$

Belajar jarak jauh tidak tergantung pada aktifitas dosen pengajar, tidak dibatasi oleh jadwal dan tempat belajar tetapi lebih banyak tergantung pada media pembelajaran yang dikomunikasikan melalui media cetak dan non cetak dan strategi pembelajarannya dapat ditentuakan sendiri oleh mahasiswa.

Mentri pendidikan nasional dalam Surat Keputusan ( SK ) No 671/2001 pasal 1 mengemukakan bahwa "Program Pendidikan tinggi jarak jauh adalah program pendidikan dengan proses pemelajaran yang dilakukan secara jarak jauh melalui penggunaan berbagai media komunikasi, materi atau sistem pendidikan jarak jauh adalah bahan ajar yang dikembangkan dan dikemas dalam bentuk tercetak dikomunikasikan dengan media lain, yang dapat digunakan oleh mahasiswa untuk proses belajar mengajara ”. (Adam komunika UT 2002 ).

Belajar jarak jauh merupakan ciri has Universitas Terbuka yang mengandalkan media pembelajaran dalam mengkomunikasikan materi atau bahan pembelajaran kepada mahasiswa.

Dalam pembelajaran di Universitas Terbuka pada umumnya materi pelajaran diberikan secara tertulis sedangkan pada perguruan tinggi lain pada umumnya materi pelajaran di berikan dalam bentuk lisan.

Ketiga dimensi tersebut smengandung makna atau pandangan bahwa kunci belajar mandiri adlah inisiatif atau prakasa seseorang dalam belajar yang ditimbulkan oleh adanya motifasi mirni atau motifasi intrisik yang lahir dari diri mahasiswa itu sendiri.

Mahasiswa yang memiliki kemauan belajar mandiri yang tinggi akan mudah mengenal jati dirinya sendiri. Artinya dapat menyadari kelebihan dan kekurangannya sehingga seseorang termotifasi untuk belajar, serta dapat melaksananakan apa yang telah direncanakan dalam belajar.

Tidak dapat di mungkiri bahwa pendidikan jarak jauh yang dilaksanakan oleh Universitas terbuka mendapat perhatian khusus dan menarik dan memukau hati bagi masyarakat yang tinggal di ibu kota maupun yang tinggal di desa terpencil, karena dapat menjangkau dan dijangkau oleh berbagai lapisan masyarakat. Dengan sistim belajar jarak jauh calon ahasiswa atau masyarakat yang sebelumnya tidak dapat melanjutkan pendidikan pada pendidikan tinggi terutama yang tinggal di desa terpencil dengan alasan tempat kuliah pada perguruan tinggi tatap muka jaraknya jauh dan menyita waktu serta biaya yang besar. Demikian pula mereka yang terikat serta sibuk dengan tugas pokoknya masing-masing mereka lebih anyak menjatuhkan pilihan pada Universitas Terbuka karena sistem belajarnya tidak mengganggu tugas, artinya mereka dapat melanjutkan pendidikan lebih tinggi, smbil bekerja serta tidak meninggalkan tugas pokok dankeluarga .

\section{Belajar Melalui Tutorial}

Tutorial adalah suatu bentuk layanan bimbingan belajar yang di berikan kepada mahasiswa agar mereka yang mengalami kesulitan dalam belajar termotivasi untuk belajar. Tutorial dapat diartikan sebagai " Program bantuan dan bimbingan belajar yang bertujuan untuk memacu dan memicu belajar mandiri ”. ( katalog UT 2009 ).

Tutorial memiliki karakteristik yang khas dan tidak sama dengan proses mengajar tatap muka, karena dalam tutorial dosen atau tutor lebih berperan sebagai fasilitator untuk memotivasi, mengarahkan, mengendalikan proses belajar dan membantu mahasiswa untuk mengatasi masalah -masalah yang ditemukan dalam belajar. 


$\begin{array}{ll}\text { Volume } & : 05 \\ \text { Nomor } & : 02 \\ \text { Bulan } & : \text { Mei } \\ \text { Tahun } & : 2019 \\ \text { http } & : \text { //ejurnal.pps.ung.ac.id/index.php/AKSARA/index }\end{array}$

Tutirial atau bantuan belajar diutamakan pada mata-mata kuliah yantg mempunyai kesulitan tinggi. Kusus untuk program S.I PGSD mengikuti tutorial sifatnya wajib, sedangkan mata-mata kuliah yang mudah tidak di tutorialkan karena dianggap bisa dipelajari sendiri oleh mahasiswa, tetapi bila mahasiswa mengalami masalah dalam belajar pada mata kuliah tersebut, boleh di minta untuk ditutorialkan atau tutorial tutorial atas permintaan mahasiswa .(tutorial atpem).

Kenyataan di lapangan mahasiswa yang belajar sendiri sering mengalami masalah hal ini disebabkan karena :

1. Masih melekatnya kebiasaan mahasiswa belajar teragantung pada pengajar.

2. Mahasiswa belum terbiasa menggunakan bahan ajar cetak maupun non cetak yang sudah dirancang khusus untuk dapat dipelajari sendiri

3. Pada umumnya mahasiswa sudah bekerja sebagai guru dan sudah terikat dengan tugas pokok mereka masing-masing di sekolah.

4. Kurang terbiasanya mahasiswa membagi dan memanfaatkan waktu lowong dan hari-hari libur untuk digunakan belajar.

5. pada umunya mahasiswa sudah berumah tangga sehingga agak sulit memusatkan perhataian dalam belajar sendiri.

Dengan melihat keberadaan mahasiswa dengan aspek kehidupanya tersebut, maka perlu cara belajarnya dibantu dengan tutorial. Program tutorial juga dapat juga diartikan sebaga

layanan bantuan dan bimbingan belajar yang mengandung tiga pengertian atau makna sebagai berikut :

Bantuan belajar dalam kegiatan ini terjadi interaksi antara tutor dan mahasiswa. Peran tutor dalam kegiatan ini berusaha memberikan bantuan kepada mahasiswa yang mengalami hambatan atau kesulitan dalam belajar terutama dalam memecahkan masalah-masalah yang ditemukan mahasiswa dalam belajar mandiri, belajar kelompok maupun belajar dalam tutorial dengan harapan agar mahasiswa mudah memahami subtansi materi perkuliahan atau modul yang dipelajari.

Bimbingan belajar, imbingan ini lebih banyak di arahkan pada teknik tentang bagaimana belajar, sehingga penggunaan srategi dalam tutorial lebih difokuskan pada belajar mahasiswa dan tutor lebih berperan sebagai fasilitator.

Tujuan belajar, Kegiatan tutorial, tutor bukan menyampaikan sejumlah informasi atau pengetahuan yang dimilikinya untuk ditransferkan pada mahasiswa, tetapi lebih banyak menuntut partisipasi dan keikut sertaan mahasiswa dalam mengemukakan pendapat, bertanya, bertanya, berdiskusi, utuk memecahkan masalah-masalah agar mereka menemukan kepercayaan diri dan terbiasa belajar mandiri.

Langkah atau tahapan ini dapat dijelaskan ( 1 ). Belajar secara individual harus ada niat dan kemauan yang sungguh-sungguh untuk belajar, membaca modul seelum datang di tutorial meragkum materi modul yang sudah di pelajari, mencatat masalah-masalah yang tidak dapat dipecahkan sendiri. ( 2 ). Belajar dalam kelompok, kegiatanya adalah mendiskusukan materi modul yang di tutorialkan, merangkum hasil diskusi belajar kelompok, masing-masing mahasiswa berusaha membahas atau bertukar pikiran tentang masalah-masalah yang di alami ketika belajar modul secara individual, mencatat masalah-masalah yang tidak dapat di pecahkan didalam diskusi kelompok kecil, untuk di bahas dalam kegiatan tutorial dengan kelompok lain, ( 3 ). Kegiatan belajar dalam kelompok tutorial, kegiatanya adalah berusaha dapat berpartisipasi pada kegiatan tutorial serta aktif dalam diskusi kelompok dan dapat memberikan solusi pada

106 AKSARA Jurnal Ilmu Pendidikan Nonformal 


$\begin{array}{ll}\text { Volume } & : 05 \\ \text { Nomor } & : 02 \\ \text { Bulan } & : \text { Mei } \\ \text { Tahun } & : 2019 \\ \text { http } & : \text { //ejurnal.pps.ung.ac.id/index.php/AKSARA/index }\end{array}$

masalah-masalah yang di temukan baik didlam kelompok sendiri maupun kelompok yang lain, berani menyampaikan masalah yang tidak dapat di selesaikan sendiri maupun kelmpok kepada tutor untuk di bahas dan di diskusikan bersama, berpartiipasi aktif dalam menyelesaikan tugastugas yang di berikan oleh tutor, dan merangkum hasil belajar melalui tutorial secara individu.

\section{METODE PENELITIAN}

Penelitian ini dilaksanakan pada kelopok belajar mahasiswa program SI PGSD yang sedang belajar di Universitas Terbuka UPBJJ-UT Gorontalo yang tinggal di desa terpencil yaitu desa Bululi Kecamatan Asparaga Kabupaten Gorontalo.

Pendekatan yang digunakan dalam penelitian ini adalah pendekatan kualikatif dengan jenis penelitian deskriptif.

Penelitian ini di maksudkan untuk mengetahui kontribusi terhadap mahasiswa yang sementara kuliah dengan sistim belajar jarak jauh. Bagdan dan Taylor mengemukakan "Metodologi kualitatif sebagai presedur penelitan yang menghasilkan data deskriptif berupa kata-kata tertulis atau lisan dari orang -orang dan perilaku yang dapat diamati ". (Moleong, 2004. 4).

Data pada penelitian ini adalah data yang berhubungan dengan aspek belajar jarak jauh, belajar mandiri, belajar lewat tutorial, penggunaan waktu belajar, biaya kuliah.dan manfaat belajar modul.

Pengumpualan data dalam peneliytian ini adalah menggunakan wawancara secara langsung kepada sumber data atau informan dengan menggunakan alat bantu berupa buku catatan alat rekaman agar data yang di peroleh melalui wawancara dapat diterima dengan jelas. Menurut Ester Berg mengemukakan " Wawancara adalah merupakan pertemuan dua orang untuk bertukar informasi dan ide melalui tanya jawab, sehingga dapat dikonstruksikan makna dalam suatu topik tertentu ". ( Dalam Sugiyono 2005.72 ).

Data yang diperoleh dari lapangan dianalisis sercara induktif artinya didasarkan pada kenyataan yang ada di lapangan, bukan didasarkan atas pemikiran dan pemahaman subjektif dari peneliti.

\section{HASIL PENELITIAN DAN PEMBAHASAN}

Rekapitulasi pokok poko temuan yang diperoleh melalui wawancara terhadap sepuluh orang informan yang dijadikan sampel.

1. Pertanyaan : Manfaat apa yang anda peroleh belajar melalui jarak jauh

Table 1

\begin{tabular}{|l|l|l|l|}
\hline NO & Pokok - Pokok Temuan & $\begin{array}{l}\text { Frekwensi Jawaban } \\
\text { Informan }\end{array}$ & $\begin{array}{l}\text { Presentasi } \\
(\%)\end{array}$ \\
\hline 1. & $\begin{array}{l}\text { Sangat membantu kami yang } \\
\text { tinggal di desa terpencil }\end{array}$ & 9 & 90 \\
2. & $\begin{array}{l}\text { Tidak meninggalkan tugas pokok } \\
\text { Tidak meninggalkan keluarga } \\
\text { 3. }\end{array}$ & 10 & 100 \\
4. & $\begin{array}{l}\text { Kami terbantu untuk dapat } \\
\text { melanjutkan pendidikan tinggi }\end{array}$ & 9 & 100 \\
\hline
\end{tabular}

Berdasarkan hasil wawancara dengan informan atau mahasiswa ternyata memberikan masukan bahwa belajar jarak jauh memberikan kontribusi seperti data yang tercamtum pada 


$\begin{array}{ll}\text { Volume } & : 05 \\ \text { Nomor } & : 02 \\ \text { Bulan } & : \text { Mei } \\ \text { Tahun } & : 2019 \\ \text { http } & : / / \text { ejurnal.pps.ung.ac.id/index.php/AKSARA/index }\end{array}$

tabel 1. Yaitu nomor 1 dengan preseantansi $90 \%$, nomor 2 dengan presentasi $100 \%$, nomor 3 dengan presentasi 100\% dan no9mor 4 dengan presentasi $90 \%$.

2. Pertanyaan : Apa kelebihanya bagi anda belajar mandiri

Table 2

\begin{tabular}{|l|l|l|l|}
\hline NO & Pokok - Pokok Temuan & $\begin{array}{l}\text { Frekwensi Jawaban } \\
\text { Informan }\end{array}$ & $\begin{array}{l}\text { Presentasi } \\
(\%)\end{array}$ \\
\hline 1. & Dapat belajar sendiri di rumah & 9 & 90 \\
2. & Kegiatan belajar di atur sendiri. & 8 & $80 \%$ \\
3. & Belajar dengan inisiatif sendiri. & 10 & $100 \%$ \\
4. & $\begin{array}{l}\text { Materi pelajaran yang dipelajari } \\
\text { ditentukan sendiri. }\end{array}$ & 9 & $90 \%$ \\
5. & $\begin{array}{l}\text { Belajar tidak tergantug pada dosen } \\
\text { pengajar. }\end{array}$ & 7 & $70 \%$ \\
\hline
\end{tabular}

Masukan yang diperoleh dari informan atau mahasiswa melalui wawancara tentang belajar mandiri seperti yang terdapat pada tabel no 2, ternyata pada nomor urut 1 presentasi $90 \%$, nomor urut $280 \%$, nomor urut $3100 \%$, nomor urut $490 \%$ dan nomor urut $570 \%$

3. Pertanyaan : Manfaat apa yang anda peroleh belajar melalui tutorial tatap muka?

Table 3

\begin{tabular}{|l|l|l|l|}
\hline NO & Pokok - Pokok Temuan & $\begin{array}{l}\text { Frekwensi Jawaban } \\
\text { Informan }\end{array}$ & $\begin{array}{l}\text { Presentasi } \\
(\%)\end{array}$ \\
\hline 1. & $\begin{array}{l}\text { Kami dapat belajar dengan teman } \\
\text { Mendapat bimbiungan belajar dari } \\
\text { tutor } \\
\text { Mudah menyelesaikan tugas-tugas } \\
\text { belajar }\end{array}$ & 9 & $\begin{array}{l}90 \% \\
100 \%\end{array}$ \\
3. & $\begin{array}{l}\text { Pemahaman kami tentang modul } \\
\text { lebih luas } \\
\text { Belajar tidak merasa kesepian. }\end{array}$ & 7 & $80 \%$ \\
5. & 9 & $70 \%$ \\
\hline
\end{tabular}

Masukan-masukan yang diperoleh melalui wawancara terhadap informan atau mahasiswa tentang layanan belajar tentang tutorial tatap muka, data pada tabel 3 menunjukan bahwa nomor 1 dengan presentasi $90 \%$, nomor 2 dengan presentasi 100\%, nomor 3 dengan presentasi $80 \%$, nomor 4 dengan presentasi $70 \%$ dan nomor 5 dengan presentasi $90 \%$.

4. Pertanyaan : Bagaiman sikap anda dalam mengatur atau memanfaatkan waktu yang tersedia.

Table 4

\begin{tabular}{|l|l|l|l|}
\hline NO & Pokok - Pokok Temuan & $\begin{array}{l}\text { Frekwensi Jawaban } \\
\text { Informan }\end{array}$ & $\begin{array}{l}\text { Presentasi } \\
(\%)\end{array}$ \\
\hline $\begin{array}{l}\text { 1. } \\
\text { 2. }\end{array}$ & $\begin{array}{l}\text { Membuat jadwal waktu belajar. } \\
\text { Memnfaatkan waktu lowong untuk } \\
\text { digunakan belajar. }\end{array}$ & 10 & $100 \%$ \\
3. & $\begin{array}{l}\text { Menggunakan waktu belajar di siang } \\
\text { hari karena tidak ada listrik. } \\
\text { Menggunakan waktu luang di di } \\
\text { sekolah untuk belajar. }\end{array}$ & 8 & $90 \%$ \\
4. & 7 & $80 \%$ \\
\hline
\end{tabular}

108 AKSARA Jurnal Ilmu Pendidikan Nonformal 


$\begin{array}{ll}\text { Volume } & : 05 \\ \text { Nomor } & : 02 \\ \text { Bulan } & : \text { Mei } \\ \text { Tahun } & : 2019 \\ \text { http } & : / / \text { ejurnal.pps.ung.ac.id/index.php/AKSARA/index }\end{array}$

Hasil wawancara dengan informan tentang kemampuan mahsiswa dlam mengataur waktu belajar, memperoleh masukan bahwa data pada tabel 4 menunjukan nomor urut 1 dengan presentasi $100 \%$, nomor 2 dengan presentasi $90 \%$, nomor 3 dengan presentasi $80 \%$ dan nomor 4 dengan presentasi $70 \%$.

5.Pertanyaan : Bagaimana menurut anda biaya yang digunakan dalam kegiatan belajar.

Table 5

\begin{tabular}{|c|c|c|c|}
\hline NO & Pokok - Pokok Temuan & $\begin{array}{l}\text { Frekwensi Jawaban } \\
\text { Informan }\end{array}$ & $\begin{array}{l}\text { Presentasi } \\
(\%)\end{array}$ \\
\hline $\begin{array}{l}1 . \\
2 .\end{array}$ & $\begin{array}{l}\text { Biaya transport lebih irit dibanding } \\
\text { dengan perguruan tinggi tatap muka. } \\
\text { Tidak mengeluarkan uang tambahan } \\
\text { selain spp. }\end{array}$ & $\begin{array}{l}10 \\
10\end{array}$ & $\begin{array}{l}100 \% \\
100 \%\end{array}$ \\
\hline
\end{tabular}

Hasil wawancara dengan informan tentang biaya yang dikeluarkan ternyata informan atau mahasiswa memberikan masukan seperti data pada tabel 4 menggambarkan bahwa nomor 1 dengan presentase $100 \%$ dan nomor 2 dengan presentase $100 \%$.

6. Pertanyaan : Apakah manfaatnya bagi anda belajar dengan menggunakan modul Table 6

\begin{tabular}{|c|c|c|c|}
\hline NO & Pokok - Pokok Temuan & $\begin{array}{l}\text { Frekwensi Jawaban } \\
\text { Informan }\end{array}$ & $\begin{array}{l}\text { Presentasi } \\
(\%)\end{array}$ \\
\hline $\begin{array}{l}1 . \\
2 . \\
3 . \\
4 .\end{array}$ & $\begin{array}{l}\text { Kami dapat belajar sendiri } \\
\text { Banyak pengetahuan yang diperoleh } \\
\text { Dengan modul ilmu kami bertambah } \\
\text { Materi dalam modul mudah } \\
\text { dipelajari. }\end{array}$ & $\begin{array}{l}10 \\
9 \\
10 \\
8\end{array}$ & $\begin{array}{l}100 \% \\
90 \% \\
100 \% \\
80 \%\end{array}$ \\
\hline
\end{tabular}

Masukan yang diperoleh melalui wawancara dengan informan tentang manfaat belajar dengan modul adalah seperti yang terdapat pada tabel 6 yaitu nomor 1 dengan presentasi $100 \%$, nomor 2 dengan presentasi $90 \%$, nomor 3 dengan presentase $100 \%$ dan nomor urut 4 presentasi $80 \%$.

\section{PENUTUP}

Hadirnya Universitas Terbuka dengan sistim belajar jarak jauh guru-guru yang tingal di desa terpencil yang sebelumnya mengajar dengan ijazah SLTA kini sudah termotifasi untuk belajar dan sudah melanjutkan pendidikan program S1 PGSD. Mahasiswa dapat belajar sambil mengajar atau tidak meninggalkan tugas pokok dan keluarga.

Dengan media cetak dan non cetak yang mengkomunikasikan materi pembelajaran dapat dipelajari sendiri membuat mahasiswa sudah mampu belajar mandiri artinya sudah dapat berinisiatif sendiri untuk mengatur strategi kegiatan belajar yaitu kapan belajar, dimana belajar, dengan siapa belajar, serta apa yang dipelajari.

Dengan layanan bantuan belajar melalui tutorial tatap muka mahasiswa dapat menyelesaikan masaalah belajar yang dialami sendiri maupun tugas-tugas daam.belajar. Dapat berdiskusi bersama teman dalam kelompok dan antar kelompok yang lain yang dibimbing oleh seorang 


$\begin{array}{ll}\text { Volume } & : 05 \\ \text { Nomor } & : 02 \\ \text { Bulan } & : \text { Mei } \\ \text { Tahun } & : 2019 \\ \text { http } & : / / \text { ejurnal.pps.ung.ac.id/index.php/AKSARA/index }\end{array}$

dosen atau tutor sebagai fasilitator sehingga suasana belajar lebih kondusif, semarak dan mahasiswa belajar tidak merasa kesepian.

\section{DAFTAR PUSTAKA}

Anggoro, Toha, Dkk. 2007. Metode Penelitian. Jakarta: Universitas Terbuka.

Anita, dkk. 2007. Strategi Pembelajaran di Sekolah Dasar. Jakarta : Universitas Terbuka Adam. 2002. Komunika UT No. IX. Jakarta : Universitas Terbuka

Bungin, Burhan. 2007. Data Penelitian Kualitatif. Jakarta: PT. Raja Grafindo Persada.

Brotosiswojo. 1997. Kurikulum Program Pengajaran PGSD Guru Kelas. Jakarta:

Universitas Terbuka

Moleong. 2004. Metodologi Penelitian Kualitatif. Bandung: PT. Remaja Rosda Karya

Santosa, Puji, Dkk. 2008. Materi dan Pembelajaran Bahasa Indonesia SD. Jakarta: Universitas Terbuka.

Suprayekti, dkk. 2008. Pembaharuan Pembelajaran. Jakarta : Universitas Terbuka

Sugiono. 2005. Memahami Penelitian Kualitatif. Bandung: CV. Alfabeta

Suparman. 2009. Pendidikan Jarak Jauh Teori dan Praktek. Jakarta : Universitas

Terbuka

Tim FKIP. 2006. Pedoman Tutorial Bagi Tutor. Jakarta : Universitas Terbuka

Tim Penulis FKIP. 2007. Pedoman Penyelenggaraan Program PGSD. Jakarta : Universitas

Terbuka

Tim Penulis FKIP. 2004. Pedoamn Tutor Bagi Tutor. Jakarta : Universitas Terbuka

Tim Penulis UT Katalog Universitas Terbuka. Jakarta : Universitas Terbuka

Wardani, I.G.A.K, Dkk. 1992. Pengelolaan Kegiatan Tutorial yang Eduktif.

Jakarta: Universitas Terbuka.

Winatapura, dkk. 2007. Teori Belajar dan Pembelajaran. Jakarta : Universitas Terbuka

Winatapura. 2002. Strategi Belajar Mengajar. Jakarta : Pusat Penerbitan Universitas Terbuka

110 AKSARA Jurnal Ilmu Pendidikan Nonformal 